\title{
Mangifera indica Extract (Vimang) Restored the Redox Balance in Type-1 Diabetic Patients
}

\author{
MCs Dalyla Alonso Rodriguez ${ }^{1 *}$, Dra Ela Moreno Tellez ${ }^{2}$, Frank E Medina Ali $^{3}$ and Dra Idalia Sanchez Morell ${ }^{4}$
}

${ }^{1}$ Master in Pharmaceutical Sciences in Infectious Diseases, Dr. Eduardo Agramonte Pina Provincial Pediatric Teaching Hospital, Camaguey, Cuba

${ }^{2}$ Second Degree Specialist in Laboratory Medicine and Master of Infectious Diseases, Institute of Medical Sciences, Carlos J Finlay, Camaguey, Cuba

${ }^{3}$ Second Degree Specialist in Endocrinology, Dr. Eduardo Agramonte Pina Provincial Pediatric Teaching Hospital, Camaguey, Cuba

${ }^{4}$ First Degree Specialist in Cardiology, Dr. Eduardo Agramonte Pina Provincial Pediatric Teaching Hospital, Camaguey, Cuba

\begin{abstract}
In diabetes mellitus, atherosclerosis is early, rapid, and widespread, affecting the dyslipoproteinemia secondary to hyperglycemia, lipoproteins glycosylation produced changes, making them more atherogenic and generate free radicals that cause apoprotein oxidation of lipids and macromolecules nearby, we decided to evaluated the presence of oxidative stress in children with Diabetes mellitus type- 1 and demonstrated the need for antioxidants as part of drug therapy of this disease. Thirty ambulatory patients of Endocrinology were selected between 6 to 12 years of age, who had been suffering from Diabetes mellitus type-I since 3 years ago. Under their informed consent of the selected group the seric levels of antioxidant was tested: uric acid, vitamin C, bilirrubin, ceruloplasmin, albumin and cholesterol, LDLcholesterol, HDL-cholesterol, triglycerides, oxidized LDL, Vimang tablets (300 mg/24 h) was supplied for three month, and the same tests were repeated every month. Data was processed by means of descriptive statistics methods, with of absolute and relative frequency distribution, performing a hypothesis test for paired observations.
\end{abstract}

\section{Introduction}

The appearing of Diabetes mellitus (Dm) in the tender age of life, represent a serious situation for what's difficult that is to maintain under good control these patients and for the frequent development of complications several years after initiate the disease. For it, it is necessary to accomplish a precocious, forceful and efficacious treatment to avoid or to postpone the presence of those complications, to teach a new style of life to those patients and to improve the prognosis and the living conditions of the same $[1,2]$.

The free radicals are implicated not only in the diabetic's complications, but also with the etiology of diabetes [3,4]. Oxidative balance of the human and essential organism for the metabolic regulation, the production of metabolic energy, the activation and inactivation of bio molecules, the transduction of signs, the cell refill and the control of the vascular tone between other ones. If this balance (generators of reactive species) and antioxidants (preventive, kidnapper and repairer) you become unbalanced in favour of the first ones for free radical's excessive production, the weakening of the antioxidant systems or for both causes will be itself in the presence of what is known like oxidative stress [5-7].

The free radicals attack chemical present compounds in the cells (lipids, proteins and DNA), causing a series of chemical events and the appearing and peaking of the disease can conduct to disorders $[8,9]$. Vimang is a natural product once varieties studied of the tree were gotten from Mangifera indica L (mango), your principal antioxidant property comes once the presence of poly-phenols was taken for (phenols, flavonoids and tannins), terpenoids and polyunsaturated fatty acids. Carry out a protective cell effect for your capability of understanding free radicals; it catches up with textiles and organs for your elevated bioavailability [10-12].

The chemical, analytical, pharmacologic and toxicological studies so much of the active ingredient as of Vimang's formulations they allow insuring that one is in the presence of a product of proven efficacy and of very low frequency of adverse effects after extra of 25 years of practice and clinical controlled assays. A very attractive product for strengthening comes from the mechanisms of antirust protection (prophylactic) of the human organism for presumably healthy people or the mechanisms of reparation of the damage caused in patients with various pathologies, fundamentally chronicles, for his effects demonstrated in the improvement of the aforementioned diseases and the patients' improvement of the quality of life $[11,12]$.

For it before exposed we intended to evaluate the presence of oxidative stress in children with diabetes mellitus type1 and demonstrated the need of the use of antioxidant as part of Vimang's pharmacologic therapy of this disease through the oral administration of tablets.

\section{Methods}

A study on 30 patients attending the Endocrinology Clinic of the Dr. Eduardo Agramonte Pina Provincial Pediatric Teaching Hospital, Camaguey in the period from March to June 2009.

\section{Inclusion criteria}

Outpatient diagnosed with type-1 diabetes mellitus, aged 5-16 years and more than three years of disease progression.

\section{Exclusion criteria}

- Patients hospitalized for decompensation of the disease.

- Patients with diseases associated with diabetes mellitus.

*Corresponding author: MCs Dalyla Alonso Rodriguez, Dr. Eduardo Agramonte Pina Provincial Pediatric Teaching Hospital, Camaguey, Cuba, E-mail: dalyla@finlay.cmw.sld.cu

Received November 21, 2011; Accepted January 12, 2012; Published January 16,2012

Citation: Alonso Rodriguez MD, Moreno Tellez DE, Medina Ali FE, Sanchez Morell DI (2012) Mangifera indica Extract (Vimang) Restored the Redox Balance in Type-1 Diabetic Patients. Biochem \& Anal Biochem 1:107. doi:10.4172/21611009.1000107

Copyright: (c) 2012 Alonso Rodriguez MD, et al. This is an open-access article distributed under the terms of the Creative Commons Attribution License, which permits unrestricted use, distribution, and reproduction in any medium, provided the original author and source are credited. 
- Patients who have taken medications that interfere with lipid levels and/or identify biological antioxidants.

- Patients with adverse reactions to Vimang.

Under informed consent of the parents as proof of approval that the child will participate in the investigation were taken fasting blood samples for determination of total cholesterol (enzymatic method), triglycerides (enzymatic method), LDL, HDL Cholesterol (Enzymatic method), uric acid (enzymatic method), vitamin C (chemical method with 2.4 dinitrophenylhydrazine), bilirubin (Gendrasik Grof), glycemia (Rapiglucotest), ceruloplasmin (Ravin modified), and albumin (Bromocresol Green), a marker of stress oxidative identified oxidized LDL levels (enzymatic method precipitation with PEG 6000).

Vimang tablets $(300 \mathrm{mg} / 24 \mathrm{~h}$ ) were administered for three months, taking the measurements of lipids, serum antioxidants, and oxidized LDL in each month in order to demonstrate the presence and correction of oxidative stress, we compared the results obtained.

The data were processed using descriptive statistics, with distribution of absolute and relative frequency, performing a hypothesis test for paired observations.

\section{Results}

Before treatment with Vimang showed decreased levels of vitamin C (33\%), ceruloplasmin (17\%) and albumin (63\%) in all the patients had at least one of the specific antioxidants decreased (Table 1).

Before the treatment the vitamin Clevels found decreased, the same they went increasing monthly even to become stabilized (Figure1-3).

Regarding the lipid profile were detected increased levels of

\begin{tabular}{|l|l|l|l|l|}
\hline Parameter & Before treatment & 1st Month & 2nd Month & 3rd Month \\
\hline Vitamin $\mathrm{C}(\mu \mathrm{mol} / \mathrm{L})$ & $35.8 \pm 26.7$ & $38.6 \pm 23.8$ & $44.5 \pm 22.6$ & $52.9 \pm 29.1$ \\
\hline Uric acid $(\mu \mathrm{mol} / \mathrm{L})$ & $214 \pm 41$ & $236 \pm 29$ & $250 \pm 46$ & $282 \pm 106$ \\
\hline Bilirrubin $(\mu \mathrm{mol} / \mathrm{L})$ & $7.5 \pm 2.4$ & $8.7 \pm 1.3$ & $11.1 \pm 0.9$ & $12.8 \pm 9.0$ \\
\hline Ceruloplasmin $(\mathrm{mg} \%)$ & $34.9 \pm 4.7$ & $35.4 \pm 3.8$ & $35.8 \pm 2.4$ & $36.9 \pm 8.6$ \\
\hline Albumin $(\mathrm{g} / \mathrm{L})$ & $32 \pm 6.3$ & $33 \pm 9.1$ & $34 \pm 3.5$ & $36 \pm 8.6$ \\
\hline Total Cholesterol $(\mathrm{mmol} / \mathrm{L})$ & $4.7 \pm 1.4$ & $4.6 \pm 0.9$ & $4.7 \pm 3.5$ & $4.7 \pm 5.8$ \\
\hline Triglycerides $(\mathrm{mmol} / \mathrm{L})$ & $3.8 \pm 1.1$ & $3.7 \pm 0.6$ & $3.8 \pm 1.4$ & $3.4 \pm 1.7$ \\
\hline HDL-Cholesterol $(\mathrm{mmol} / \mathrm{L})$ & $1.9 \pm 0.3$ & $1.8 \pm 0.5$ & $2.1 \pm 0.1$ & $2.4 \pm 0.8$ \\
\hline LDL-Cholesterol $(\mathrm{mmol} / \mathrm{L})$ & $3.0 \pm 0.6$ & $3.2 \pm 0.4$ & $3.0 \pm 0.2$ & $3.4 \pm 0.8$ \\
\hline Oxidized LDL $(\mu \mathrm{g} / \mathrm{ml})$ & $47.4 \pm 29.9$ & $43 \pm 18.3$ & $39 \pm 15.0$ & $31.2 \pm 11.7$ \\
\hline
\end{tabular}

Probability index: $\mathrm{P}<=0.05$ for all the measured compounds

Table 1: Average levels of antioxidants and lipids in patients before and during treatment with Vimang.

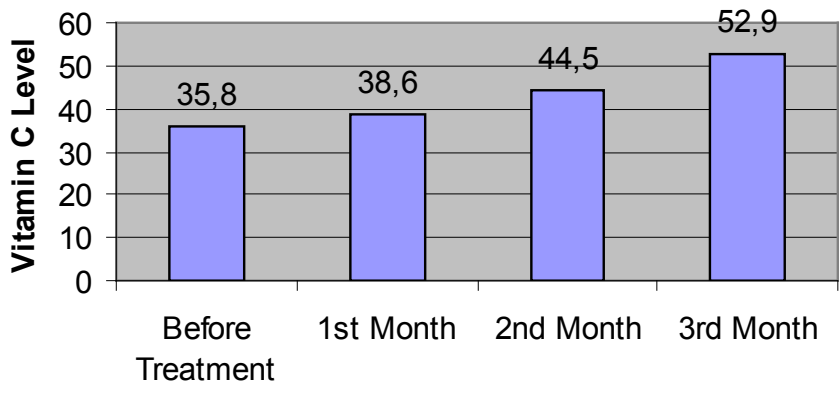

Figure 1: Mean Levels of Vitamin $C(\mu \mathrm{mol} / \mathrm{L})$ during the treatment with Vimang in all the patients of the study.

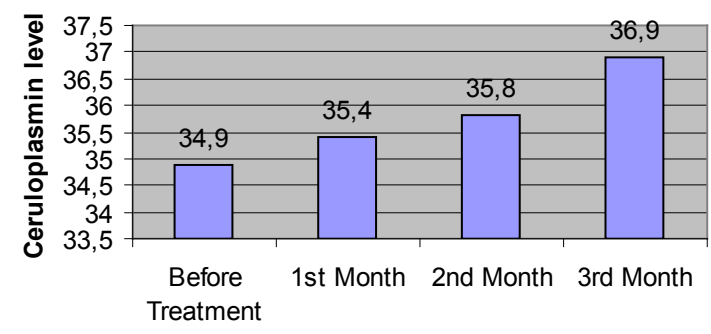

Figure 2: Mean Levels of Ceruloplasmin ( $\mathrm{mg} \%$ ) during the treatment with Vimang in all the patients of the study.

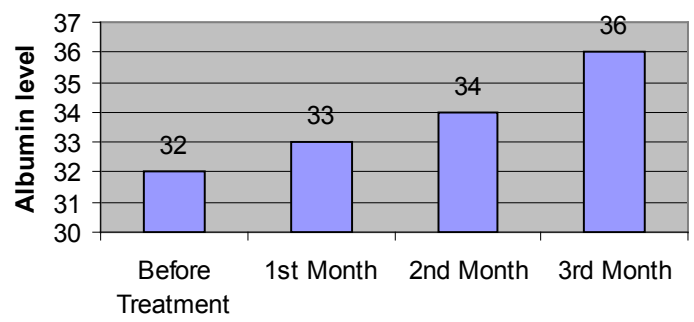

Figure 3: Mean Levels of Albumin ( $\mathrm{g} / \mathrm{L}$ ) during the treatment with Vimang in all the patients of the study.

triglycerides (13\%), total cholesterol (50\%) and oxidized LDL, the main marker of oxidative stress in $100 \%$ of patients.

The figure 4 show the significative reduction of LDLox level during the treatment with Vimang.

In $93 \%$ of patients in blood glucose levels were high without throwing hospitalization criteria, therefore it was concluded that they had a poor metabolic control of the disease, which is basically attributed to the diet [10-12].

At the conclusion Vimang treatment, showed that increased serum levels of certain antioxidants, lipid levels as total cholesterol and LDL-C remained unchanged, HDL-C increased slightly and significantly reduced oxidized LDL. This suggests a decrease in the levels of lipoperoxides and therefore greater protection against oxidative damage of lipids thus might prevent or delay complications of diabetes mellitus in whose etiology involves oxidative stress.

\section{Discussion}

The decrease in antioxidant reserves produced the accumulation of free radicals, on the other hand, uric acid acts as an antioxidant together with vitamin $\mathrm{C}$, the former has an unshared electron pair that captures the reactive oxygen species and the yield to vitamin $\mathrm{C}$, forming a safe complex that is easily removed in the organism, finding reduced levels of either establishing the imbalance [7-9].

Studies in the Clinical Laboratory provincial pediatric teaching hospital "Eduardo Agramonte Piña" have shown that the sensitivity of LDL to oxidation is not associated with hyperlipidemia, but the degree of oxidative stress, which can unbalance the disease, the principal marker of the oxidative stress was the LDLox, due to this is the more atherogenic lipoprotein and the response of several events in the oxidative state.

Oxidation the LDL's alive in depends of several factors, some of whom they are subordinate to the midway like the activity of the 


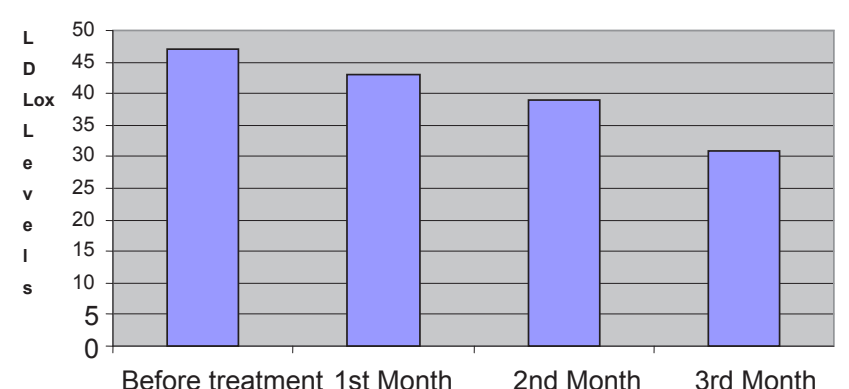

Figure 4: Mean Levels of LDLox during the treatment of the patients.

lipooxigenasa in macrophages or free radicals' selection principal the anion superoxide that they are responsible of the peroxidation $[1,3]$.

It has been demonstrated in diabetic patients than alterations for glucosylation of the structure of the LDL, they turn her the oxidation into a most prone particle, and this will be subject to the frequency of hyper-glycaemia. The LDL's oxidation not only results in a deep alteration of the lipids, but also of proteins $[5,6]$.

The diagnosis of the stress oxidative for the clinical laboratory can sell off of easy way if we are able to lead spectrophotometric technicians toward the quest of the peroxidising- antioxidant unbalance that is triggered in any situation of stress itself. It is well known that this diagnosis comes true in a rut through the measurement of the damages caused on important macromolecules at its organism and no for these free radicals' direct measurement than they are approximately intangible for your fleeting nature $[14,15]$.

\section{Conclusions}

- There is an oxidative stress in children affected by type-1 diabetes mellitus for $76 \%$ of diagnosed patients.

- In $100 \%$ of patients had a poor metabolic control of the disease associated with diet.

- It corrects the oxidative stress in diabetic children $300 \mathrm{mg}$ daily for 3 months Vimang.

\section{Recommendations}

- Including the pharmacological treatment of type-1 diabetes mellitus an antioxidant drug to correct the oxidative stress.

- Insist on the metabolic control of the disease, based on achieving a balanced diet.

\section{References}

1. Andrieva-Gateva P (1999) Insulin Resistance and Oxidative Stress. Vutr Boles 31: 9-19.

2. Medaoui AE, Champlain J (2002) Prevention of hypertension, insulin resistance, and oxidative stress by alpha-lipoic acid. Hypertension 39: 303-307.

3. Asayama K, Uchida N, Nakane T, Hayashibe H, Doboshi K, et al. (1993) Antioxidantsin the serum af children whith insulin-dependent diabetes mellitus. Free Radic Biol Med 15: 597-602.

4. Ramos V, Guell R, Vera M, Dávalos A, Ferraro M, et al. (1998) Consenso latinoamericano sobre diabetes en el niño y el adolescente. Cartagena de Indias Colombia: Novo care 7-21.

5. Martínez G, Giuliani A, León OS, Pérez G, Núñez Selles AJ (2001) Effect of Mangifera indica L extract (QF808) on protein and hepatic microsome peroxidation. Phytother Res 15: 581-585.

6. Martínez Sánchez G, Candelario-Jalil E, Giuliani A, León OS, Sam S, et al (2001) Mangifera indica L extract (QF808) reduces ischaemia-induced neuronal loss and oxidative damage in the gerbil brain. Free Radic Res 35: 465-473.
7. Loy S, Simón R, Delgado R (2002) Vimang: un potencial protector de la peroxidación lipídica en lipoproteínas de baja densidad. Rev Cubana Invest Biomed 21: 167-170.

8. Céspedes Cabrera T, Sánchez Serrano D (2000) Algunos aspectos sobre el estés oxidativo, el estado antioxidante y la terapia de suplementación. Rev Cubana Cardiol 14: 55-60.

9. König D, Wagner KH, Elmadfa I, Berg A (2001) Exercise and oxidative stress: significance of antioxidants with reference to inflammatory, muscular, and systemic stress. Exerc Immunol Rev 7: 108-133.

10. Martínez Sánchez G, Delgado Hernández R, Garrido Garrido G, Guevara García M, García Rivera D, et al. (2003) Vimang, Nuevo producto natural antioxidante. Myths and realities of antioxidant therapy, Ministry of Public Health, Havana.

11. Gil L, Martínez G, González I, Tarinas A, Alvarez A, et al. (2002) Effects of Vimang on oxidative stress and marker of disease progession in HIVIAIDS patients. Free Rad Res 36: 107-108.

12. Beltrán A, Ledón N, Romay C, Sironi M, Quintero G, et al. (2004) In vivo and in Vitro antiinflammatory activity of Mangifera indica L Extract (Vimang). Pharmacol Res 50: 143-149.

13. Molina $H$ (2001) El ácido úrico como antioxidante de los radicales libres de oxígeno en fluidos humanos. Acta Bioq Clin Latinoam 35: 69-73.

14. Delmas-Beauvieux MC, Peuchant E, Thomas MJ, Dubourg L, Pinto AP (1998) The place of electron spin resonance methods in the detection of oxidative stress in type-2 diabetes with poor glycemic control. Clin Biochem 31: 221-228.

15. Williams D, Dorchy $H$, Dufrasne D (1998) Serum antioxidant status and oxidized LDL in well-controlled young type-1 diabetic patients with and without subclinical complications. Atherosclerosis 137: 61-64. 